\title{
Against Parsimony: Three Easy Ways of Complicating Some Categories of Economic Discourse
}

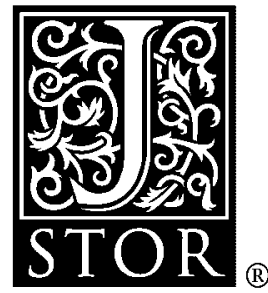

\author{
Albert O. Hirschman \\ The American Economic Review, Vol. 74, No. 2, Papers and Proceedings of the \\ Ninety-Sixth Annual Meeting of the American Economic Association (May, 1984), \\ 89-96. \\ http://links.jstor.org/sici?sici=0002-8282\%28198405\%2974\%3A2\%3C89\%3AAPTEWO\%3E2.0.CO\%3B2-4
}

Stable URL:

The American Economic Review is currently published by American Economic Association.

Your use of the JSTOR archive indicates your acceptance of JSTOR's Terms and Conditions of Use, available at http://www.jstor.org/about/terms.html. JSTOR's Terms and Conditions of Use provides, in part, that unless you have obtained prior permission, you may not download an entire issue of a journal or multiple copies of articles, and you may use content in the JSTOR archive only for your personal, non-commercial use.

Please contact the publisher regarding any further use of this work. Publisher contact information may be obtained at http://www.jstor.org/journals/aea.html.

Each copy of any part of a JSTOR transmission must contain the same copyright notice that appears on the screen or printed page of such transmission.

JSTOR is an independent not-for-profit organization dedicated to creating and preserving a digital archive of scholarly journals. For more information regarding JSTOR, please contact support@jstor.org. 


\title{
Against Parsimony: Three Easy Ways of Complicating Some Categories of Economic Discourse
}

\author{
By Albert O. Hirschman*
}

In his well-known article on "Rational Fools," Amartya Sen asserted that "traditional [economic] theory has too little structure" (1977, p. 335). Like any virtue, so he seemed to say, parsimony in theory construction can be overdone and something is sometimes to be gained by making things more complicated. I have increasingly come to feel this way. Some years ago, I suggested that criticism from customers or "voice" should be recognized as a force keeping management of firms and organizations "on their toes," alongside with competition or "exit," and it took a book (1970) to cope with the resulting complications. Here I deal with various other realms of economic inquiry that stand similarly in need of being rendered more complex. In concluding I examine whether the various complications have some element in common - that would in turn simplify and unify matters.

\section{Two Kinds of Preference Changes}

A fruitful distinction has been made, by Sen and others, between first- and secondorder preferences, or between preferences and metapreferences, respectively. I shall use the latter terminology here. Economics has traditionally dealt only with (first-order) preferences, that is, those that are revealed by agents as they buy goods and services. But the concept of metapreference must be of concern to the economist, to the extent that he claims an interest in understanding processes of economic change. Its starting point is a very general observation on human nature: men and women have the ability to step back from their "revealed" wants, voli-

\footnotetext{
*Professor of Social Science, The Institute for Advance Study, Princeton, NJ 08540. A more complete version of this paper will appear in Bulletin of the American Academy of Arts and Sciences, forthcoming.
}

tions, and preferences, to ask themselves whether they really want these wants and prefer these preferences, and consequently to form metapreferences that may differ from their preferences. Unsurprisingly, it is a philosopher, Harry Frankfurt (1971), who first put matters this way. He argued that this ability to step back is unique in humans, but is not present in all of them. Those who lack this ability he called "wantons": they are entirely, unreflectively in the grip of their whims and passions.

As I have pointed out before (1982, p. 71), certainty about the existence of metapreferences can only be gained through changes in preferences, that is, through changes in actual choice behavior. If preferences and metapreferences always coincide so that the agent is permanently at peace with himself no matter what choices he makes, then the metapreferences hardly lead an independent existence and are mere shadows of the preferences. If, on the other hand, the two kinds of preferences are permanently at odds so that the agent always acts against "his better judgment," then again the metapreference can not only be dismissed as wholly ineffective, but doubts will arise whether it is really there at all.

Changes in choice behavior are therefore essential for validating the concept of metapreferences; conversely, this concept is useful in illuminating the varied nature of preference change, for it is now possible to distinguish between two kinds of preference changes. One is the reflective kind, preceded as it is by the formation of a metapreference that is at odds with the observed and hitherto practiced preference. But there are also preference changes that take place without any elaborate antecedent development of metapreferences. Following Frankfurt's terminology, the unreflective changes in preferences might be called "wanton." These are the 
preference changes economists have primarily focused on: haphazard, publicity-induced, and generally minor (apples vs. pears) change in tastes. In contrast, the nonwanton change of preference is not really a change in tastes at all. A taste is almost defined as a preference about which you do not argue-de gustibus non est disputandum. A taste about which you argue, with others or yourself, ceases ipso facto being a taste-it turns into a value. When a change in preferences has been preceded by the formation of a metapreference much argument has obviously gone on within the divided self; it typically represents a change in values rather than a change in tastes.

Given the economists' concentration on, and consequent bias for, wanton preference changes, changes of the reflective kind have tended to be downgraded to the wanton kind by assimilating them to changes in tastes: thus patterns of discriminatory hiring have been ascribed to a "taste for discrimination" (Gary Becker, 1957) and increases in protectionism have similarly been analyzed as reflecting an enhanced "taste for nationalism" (Harry Johnson, 1965). Such interpretations strike me as objectionable on two counts: first, they impede a serious intellectual effort to understand what are strongly held values and difficult-to-achieve changes in values rather than tastes and changes in tastes; second, the illusion is fostered that "raising the cost" of discrimination (or nationalism) is the simple and sovereign policy instrument for getting people to indulge less in those odd "tastes."

In the light of the distinction between wanton and nonwanton preference changes, or between changes in tastes and changes in values, it also becomes possible to understand-and to criticize - the recent attempt of Becker and George Stigler (1977) to do without the notion of preference changes for the purpose of explaining changes in behavior. Equating preference changes to changes in what they themselves call "inscrutable, often capricious tastes" (p. 76), they find, quite rightly, any changes in those kinds of tastes (our wanton changes) of little analytical interest. But in their subsequent de- termination to explain all behavior change through price and income differences, they neglect one important source of such change: autonomous, reflective change in values. For example, in their analysis of beneficial and harmful addiction they take the elasticity of the individual's demand curve for music or heroin as given and, it would seem, immutable. May I urge that changes in values do occur from time to time in the lives of individuals, of generations, and from one generation to another, and that those changes and their effects on behavior are worth exploring - that, in brief, de valoribus est disputandum?

\section{Two Kinds of Activities}

From consumption I now turn to production and to human activities such as work and effort involved in achieving production goals. Much of economic activity is directed to the production of (private) goods and services that are then sold in the market. From the point of view of the firm, the activity carries with it a neat distinction between process and outcome, inputs and outputs, or costs and revenue. From the point of view of the individual participant in the process, a seemingly similar distinction can be drawn between work and pay or between effort and reward. Yet there is a well-known difference between the firm and the individual: for the firm any outlay is unambiguously to be entered on the negative side of the accounts whereas work can be more or less irksome or pleasant - even the same work can be felt as more pleasant by the same person from one day to the next. This problem, in particular its positive and normative consequences for income differentials, has attracted the attention of a long line of economists starting with Adam Smith. Most recently Gordon Winston has distinguished between "process utility" and "goal utility" (1982, pp. 193-97). While such a distinction makes it clear that the means to the end of productive effort need not be entered on the negative side in a calculus on satisfaction, it keeps intact the basic instrumental conception of work, the means-end dichotomy on 
which our understanding of the work and production process has been essentiallyand, up to a point, so usefully - based.

But there is need to go further if the complexity and full range of human activities, productive and otherwise, are to be appreciated. Once again, more structure would be helpful. The possible existence of wholly noninstrumental activities is suggested by everyday language: it speaks of activities that are undertaken "for their own sake" and that "carry their own reward." These are somewhat trite, unconvincing phrases: after all, any sustained activity, with the possible exception of pure play, is undertaken with some idea about an intended outcome. A person who claims to be working exclusively for the sake of the rewards yielded by the exertion itself is usually suspect of hypocrisy: one feels he is "really" after the money, the advancement or-at least - the glory, and thus is an instrumentalist after all.

Some progress can be made with the matter by looking at the varying predictability of the intended outcome of different productive activities. Certain activities, typically of a routine character, have perfectly predictable outcomes. With regard to such tasks, there is no doubt in the individual's mind that effort will yield the anticipated outcome-an hour of labor will yield the well-known, fully visualized result as well as entitle the worker, if he has been contracted for the job, to a wage that can be used for the purchase of desired (and usually also well-known) goods. Under these conditions, the separation of the process into means and ends, or into costs and benefits, occurs almost spontaneously and work assumes its normal instrumental character.

But there are many kinds of activities, from that of a research and development scientist to that of a composer or an advocate of some public policy, whose intended outcome cannot be relied upon to materialize with certainty. Among these activities there are some-applied laboratory research may be an example - whose outcome cannot be predicted for any single day or month; nevertheless, success in achieving the intended result steadily gains in likelihood as the period during which work is carried on gets longer. In this case, the uncertainty is of a probabilistic nature and one can speak of a certainty equivalent with regard to the output of the activity in any given period so that, once again, the separation of the process into means and ends is being experienced and work of this sort largely retains its instrumental cast.

I now come to a more puzzling kind of nonroutine activities. From their earliest origins, men and women appear to have allocated a considerable portion of their time to undertakings whose success is simply unpredictable. These are activities such as the pursuit of truth, beauty, justice, liberty, community, friendship, love, salvation, and so on. As a rule, these pursuits are of course carried on through a variety of exertions for apparently limited and specific objectives (writing a book, participating in a political campaign, etc.). Nevertheless, an important component of the activities thus undertaken is best described not as labor or work, but as striving - a term that precisely intimates the lack of a reliable relation between effort and result. A means-end or cost-benefit calculus is impossible under the circumstances.

The question now arises why such activities should be taken up at all, as long as their successful outcome is so wholly uncertain. Moreover, they certainly are not always pleasant in themselves-in fact some of them can be quite strenuous or highly dangerous. Do we have here then another paradox or puzzle, one that relates not just to voting (why do "rational" people bother to vote?), but to a much wider and most vital group of human activities? I suppose we do-from the point of view of instrumental reason, noninstrumental action is bound to be something of a mystery. But I have proposed an at least half-rational explanation: these noninstrumental activities whose outcome is so uncertain are strangely characterized by a certain fusion of (and confusion between) striving and attaining (see my 1982 book, pp. 84-91). He who strives after truth (or beauty) frequently experiences the conviction, fleeting though it may be, that he has found (or achieved) it. He who participates in a move- 
ment for liberty or justice frequently has the experience of already bringing these ideals within reach. In Pascal's formulation: "The hope Christians have to possess an infinite good is mixed with actual enjoyment...for they are not like people who would hope for a kingdom of which they, as subjects, have nothing; rather, they hope for holiness, and for freedom from injustice, and they partake of both" (Pensées, 540, Brunschvicg edition, my translation).

This fusion of striving and attaining is a fact of experience that goes far in accounting for the existence and importance of noninstrumental activities. As though in compensation for the uncertainty about the outcome, the striving effort is colored by the goal and in this fashion makes for an experience that is very different from merely agreeable, pleasurable or even "stimulating": in spite of its frequently painful character it has a well-known "intoxicating" quality.

The foregoing interpretation of noninstrumental action is complemented by an alternative view which has been proposed by the sociologist Alessandro Pizzorno (1983). For him, participation in politics is of ten engaged in because it enhances one's feeling of belonging to a group. I would add that noninstrumental action in general makes you feel more like a "real person." Such action can then be considered, in economic terms, as an investment in individual and group identity. The feeling of having achieved belongingness and personhood may of course be just as evanescent as the fusion of striving and attaining to which I referred earlier. The two views are related attempts at achieving an uncommonly difficult insight: to think instrumentally about the noninstrumental.

But why should economics be concerned with all this? Is it not enough for this discipline to attempt an adequate account of man's instrumental activities - $\mathbf{a}$ vast area indeed-while leaving the other, somewhat murky regions alone? Up to a point such a limitation made sense. But as economics has grown more ambitious, it becomes of increasing importance to appreciate that the meansend, cost-benefit model is far from covering all aspects of human activity and experience. Take the analysis of political action, an area in which economists have become interested as a natural extension of their work on public goods. Here the neglect of the noninstrumental mode of action was responsible for the inability of the "economic approach" to understand why people bother to vote and why they engage from time to time in collective action.

Once the noninstrumental mode is being paid some attention it becomes possible to account for these otherwise puzzling phenomena. It is the fusion of striving and attaining, characteristic of noninstrumental action, that led me to a conclusion exactly opposite to the "free ride" argument with respect to collective action:

since the output and objective of collective action are... a public good available to all, the only way an individual can raise the benefit accruing to him from the collective action is by stepping up his own input, his effort on behalf of the public policy he espouses. Far from shirking and attempting to get a free ride, a truly maximizing individual will attempt to be as activist as he can manage, .... [1982, p. 86]

The preceding argument does not imply, of course, that citizens will never adopt the instrumental mode of action with respect to action in the public interest. On the contrary, quite a few of them may well move from one mode to the other, and such oscillations could help explain the observed instability both of individual commitment and of many social movements in general.

A better understanding of collective action is by no means the only benefit that stands to flow from a more open attitude toward the possibility of noninstrumental action. As has been argued earlier, a strong affinity exists between instrumental and routine activities, on the one hand, and between noninstrumental and nonroutine activities, on the other. But just as I noted the existence of nonroutine activities that are predominantly instrumental (in the case of an applied research laboratory), so can routine work have more or less of a noninstrumental component, as Veblen stressed in The Instinct of Workmanship. Lately the conviction has 
gained ground that fluctuations in this component must be drawn upon to account for variations in labor productivity and for shifts in industrial leadership. It does make a great deal of difference, so it seems, whether people look at their work as "just a job" or also as part of some collective celebration.

\section{III. "Love": Neither Scarce Resource Nor Augmentable Skill}

My next plea for complicating economic discourse also deals with the production side, but more specifically with the role of one important prerequisite or ingredient known variously as morality, civic spirit, trust, observance of elementary ethical norms, and so on. The need of any functioning economic system for this "input" is widely recognized. But disagreement exists over what happens to this input as it is being used.

There are essentially two opposite models of factor use. The traditional one is constructed on the basis of given, depletable resources that get incorporated into the product. The scarcer the resource the higher its price and the less of it will be used by the economizing firm in combination with other inputs. A more recent model recognizes the possibility of "learning by doing" (Kenneth Arrow, 1962). Use of a resource such as a skill has the immediate effect of improving the skill, of enlarging (rather than depleting) its availability. The recognition of this sort of process was a considerable, strangely belated insight.

Because the "scarce resource" model has long been dominant, it has been extended to domains where its validity is highly dubious. Some thirty years ago, Dennis Robertson wrote a characteristically witty paper entitled "What Does the Economist Economize?" (1956). His often cited answer was: love, which he called "that scarce resource" (p. 154). Robertson explained, through a number of well-chosen illustrations from the contemporary economic scene, that it was the economist's job to create an institutional environment and pattern of motivation where as small a burden as possible would be placed, for the purposes of society's functioning, on this thing "love," a term he used as a shortcut for morality and civic spirit. In so arguing, he was of course at one with Adam Smith who celebrated society's ability to do without "benevolence" (of the butcher, brewer, and baker) as long as individual "interest" was given full scope. Robertson does not invoke Smith, quoting instead a telling phrase by Marshall: “Progress chiefly depends on the extent to which the strongest and not merely the highest forces of human nature can be utilized for the increase of social good" (p. 148). This is yet another way of asserting that the social order is more secure when it is built on interest rather than on love or benevolence. But the sharpness of Robertson's own formulation makes it possible to identify the flaw in this recurrent mode of reasoning.

Once love and particularly public morality is equated to a scarce resource, the need to economize it seems self-evident. Yet a moment's reflection is enough to realize that the analogy is not only questionable, but a bit absurd-and therefore funny. Take, for example, the well-known case of the person who drives in the morning rush hour and quips, upon yielding to another motorist: "I have done my good deed for the day; for the remainder, I can now act like a bastard." What strikes one as funny and absurd here is precisely the assumption, on the part of our driver, that he comes equipped with a strictly limited supply of good deeds; that, in other words, love should be treated as a scarce resource-just as Robertson claimed. We know instinctively that the supply of such resources as love or public spirit is not fixed or limited as may be the case for other factors of production. The analogy is faulty for two reasons: first of all, these are resources whose supply may well increase rather than decrease through use; second, these resources do not remain intact if they stay unused; like the ability to speak a foreign language or to play the piano, these moral resources are likely to become depleted and to atrophy if not used.

In a first approximation, then, Robertson's prescription appears to be founded on a confusion between the use of a resource and the practice of an ability. While human abilities and skills are valuable economic re- 
sources, most of them respond positively to practice, in a learning-by-doing manner, and negatively to nonpractice. It was on the basis of this atrophy dynamic that the U.S. system for obtaining an adequate supply of human blood for medical purposes, with its only partial reliance on voluntary giving, has been criticized by Richard Titmuss, the British sociologist. And a British political economist, Fred Hirsch (1976), has generalized the point: once a social system, such as capitalism, convinces everyone that it can dispense with morality and public spirit, the universal pursuit of self-interest being all that is needed for satisfactory performance, the system will undermine its own viability which is in fact premised on civic behavior and on the respect of certain moral norms to a far greater extent than capitalism's official ideology avows.

How is it possible to reconcile the concerns of Titmuss-Hirsch with those seemingly opposite, yet surely not without some foundation, of Robertson, Adam Smith, and Alfred Marshall? The truth is that, in his fondness for paradox, Robertson did his position a disservice: he opened his flank to easy attack when he equated love to some factor of production in strictly limited supply that needs to be economized. But what about the alternative analogy that equates love, benevolence, and public spirit to a skill that is improved through practice and atrophies without it? This one, too, has its weak points. Whereas public spirit will atrophy if too few demands are made upon it, it is not at all certain that the practice of benevolence will indefinitely have a positive feedback effect on the supply of this "skill." The practice of benevolence yields satisfaction (makes you feel good), to be sure, and therefore feeds upon itself up to a point, but this process is very different from practicing a manual (or intellectual) skill: here the practice leads to greater dexterity which is usually a net addition to one's abilities, that is, it is not acquired at the expense of some other skill or ability. In the case of benevolence, on the other hand, the point is soon reached where increased practice does conflict with selfinterest and even self-preservation: our quip- ping motorist, to go back to him, has not exhausted his daily supply of benevolence by yielding once, but there surely will be some limit to his benevolent driving behavior, in deference to his own vital-perhaps ethically compelling - displacement needs.

Robertson had a point, therefore, when he maintained that there could be institutional arrangements which make excessive demands on civic behavior just as Titmuss and Hirsch were right in pointing to the opposite danger: the possibility, that is, that society makes insufficient demands on civic spirit. In both cases, there is a shortfall in public spirit, but in the cases pointed to by Robertson, the remedy consists in institutional arrangements placing less reliance on civic spirit and more on self-interest whereas in the situations that have caught the attention of Titmuss and Hirsch there is need for increased emphasis on, and practice of, community values and benevolence. These two parties argue along exactly opposite lines, but both have a point. Love, benevolence, and civic spirit are neither scarce factors in fixed supply, nor do they act like skills and abilities that improve and expand more or less indefinitely with practice. Rather, they exhibit a complex, composite behavior: they atrophy when not adequately practiced and appealed to by the ruling socioeconomic regime, yet will once again make themselves scarce when preached and relied on to excess.

To make matters worse, the precise location of these two danger zones-which, incidentally, correspond roughly to the complementary ills of today's capitalist and centrally planned societies-is by no means known, nor are these zones ever stable. An ideological-institutional regime that in wartime or during some other time of stress and public fervor is ideally suited to call forth the energies and efforts of the citizenry is well advised to give way to another that appeals more to private interest and less to civic spirit in a subsequent, less exalted period. Inversely, a regime of the latter sort may, because of the ensuing "atrophy of public meanings" (Charles Taylor, 1970, p. 123), give rise to anomie and unwillingness ever to sacrifice private or group interest to the pub- 
lic weal so that a move back to a more community-oriented regime would be called for.

\section{Conclusion}

I promised, earlier on, to inquire whether the various complications of traditional concepts that have been proposed have any common structure. The answer should be obvious: all these complications flow from a single source - the incredible complexity of human nature which was disregarded by traditional theory for very good reasons, but which must be spoon-fed back into the traditional findings for the sake of greater realism.

A plea to recognize this complexity was implicit in my earlier insistence that "voice" be granted a role in certain economic processes alongside "exit," or competition. The efficient economic agent of traditional theory is essentially a silent scanner and "superior statistician" (Arrow, 1978) whereas I argued that she also has considerable gifts of verbal and nonverbal communication and persuasion that will enable her to affect economic processes.

Another fundamental characteristic of humans is that they are self-evaluating beings, perhaps the only ones among living organisms. This simple fact forced the intrusion of metapreferences into the theory of consumer choice and made it possible to draw a distinction between two fundamentally different kinds of preference changes. The self-evaluating function could be considered a variant of the communication or voice function: it also consists in a person addressing, criticizing, or persuading someone, but this someone is now the self rather than a supplier or an organization to which one belongs. But let us beware of excessive parsimony!

In addition to being endowed with such capabilities as communication, persuasion and self-evaluation, man is beset by a number of fundamental, unresolved, and perhaps unresolvable tensions. A tension of this kind is that between instrumental and noninstrumental modes of behavior and action. Economics has, for very good reasons, con- centrated wholly on the instrumental mode. I plead here for a concern with the opposite mode, on the grounds 1) that it is not wholly impervious to economic reasoning; and 2) that it helps us understand matters that have been found puzzling, such as collective action and shifts in labor productivity.

Finally I have turned to another basic tension man must live with, this one resulting from the fact that he lives in society. It is the tension between self and others, between self-interest, on the one hand, and public morality, service to community, or even selfsacrifice, on the other, or between "interest" and "benevolence" as Adam Smith put it. Here again economics has concentrated overwhelmingly on one term of the dichotomy, while putting forward simplistic and contradictory propositions on how to deal with the other. The contradiction can be resolved by closer attention to the special nature of public morality as an "input."

In sum, I have complicated economic discourse by attempting to incorporate into it two basic human endowments and two basic tensions that are part of the human condition. To my mind, this is just a beginning.

\section{REFERENCES}

Arrow, Kenneth J., "The Economic Implications of Learning by Doing," Review of Economic Studies, June 1962, 29, 155- 73.

" "The Future and the Present in Economic Life," Economic Inquiry, April 1978, 16, 160.

Becker, Gary S., The Economies of Discrimination, Chicago: Chicago University Press, 1957.

and Stigler, George, "De Gustibus Non Est Disputandum," American Economic Review, March 1977, 67, 76-90.

Frankfurt, Harry G., "Freedom of the Will and the Concept of a Person," Journal of Philosophy, January 1971, 68, 5-20.

Hirsch, Fred, Social Limits to Growth, Cambridge: Harvard University Press, 1976.

Hirschman, Albert O., Exit, Voice, and Loyalty, Cambridge: Harvard University Press, 1970.

, Shifting Involvements: Private Inter- 
est and Public Action, Princeton: Princeton University Press, 1982.

Johnson, Harry G., "A Theoretical Model of Economic Nationalism in New and Developing States," Political Science Quarterly, June 1965, 80, 169-85.

Pizzorno, Alessandro, "Sulla razionalità della scelta democratica," Stato e Mercato, April 1983, No. 7, 3-46.

Robertson, Dennis H., "What Does the Economist Economize?," in Economic Commen- taries, London: Staples Press, 1956, 14755.

Sen, Amartya K., "Rational Fools: A Critique of the Behavioral Foundations of Economic Theory," Philosophy and Public Affairs, Summer 1977, 6, 317-44.

Taylor, Charles, The Pattern of Politics, Toronto: McClelland and Stewart, 1970.

Winston, Gordon C., The Timing of Economic Activities, Cambridge: Cambridge University Press, 1982. 